screening. Yet optic disc assessment and tonometry require little specialist skill or sophisticated equipment, and have reasonably high specificity in the detection of advanced glaucoma, these patients being the most likely to go blind, to present, and to comply with treatment. Efforts need to be made to train general medical and ophthalmic personnel in the recognition of this disease and to highlight awareness of glaucoma in both the medical community and the general population.

In conclusion, this report and the population based surveys that contributed to it, have provided estimates of current and predicted morbidity from glaucoma. Additionally, the contributions of the different types of glaucoma are predicted for which there are differing approaches in terms of diagnosis and therapy. It has been noted before that each glaucoma subtype (either open angle or angle closure) is a greater cause of visual morbidity individually than any other ocular disease, except cataract and trachoma. ${ }^{9}$ The predictions from this paper are of great importance in planning health policy from both a global and also a region specific perspective. Many of these surveys have already been used as advocacy for the planning of health policy within their respective countries and regionally. The Arab-American philosopher Kahlil Gibran (1883-1931) once said "A little knowledge that acts is worth infinitely more than much knowledge that is idle." Even within developed countries, less than half of those with glaucoma are aware of their disease. There is no doubt that more prevalence data would be useful, yet there is a need to act using the available data by improving awareness, case detection, and treatment of glaucoma worldwide.

Br J Ophthalmol 2006;90:253-254.

doi: 10.1136/bjo.2005.083527

Correspondence to: Rupert R A Bourne, FRCOphth, MD, Department of Glaucoma, Ophthalmology Service, Hinchingbrooke Hospital, Hinchingbrooke Park, Huntingdon, Cambridgeshire, PE29 6NT, UK; rupert.

bourne@|shtm.ac.uk
Competing interests: none declared

\section{REFERENCES}

1 Quigley HA. Number of people with glaucoma worldwide. Br J Ophthalmol 1996;80:389-93.

2 Thylefors BNA. The global impact of glaucoma. Bull World Health Organ 1994;72:323-6.

3 Wolfs RC, Borger PH, Ramrattan RS, et al. Changing views on open-angle glaucoma: definitions and prevalences-The Rotterdam Study. Invest Ophthalmol Vis Sci 2000;41:3309-21.

4 Foster PJ, Buhrmann R, Quigley HA, et al. The definition and classification of glaucoma in prevalence surveys. Br J Ophthalmol 2002;86:238-42

5 Thylefors B. Avoidable blindness. Bull World Health Organ 1999;77:453.

6 Resnikoff S, Pascolini D, Etya'ale D, et al. Global data on visual impairment in the year 2002. Bull World Health Organ 2004;82:844-51.

7 Crowston JG, Hopley CR, Healey PR, et al. The effect of optic disc diameter on vertical cup to disc ratio percentiles in a population based cohort: the Blue Mountains Eye Study. Br J Ophthalmol 2004;88:766-70.

8 Rotchford A. What is practical in glaucoma management? Eye 2005; 19:1125-32.

9 Quigley HA, Congdon NG, Friedman DS Glaucoma in China (and worldwide): changes in established thinking will decrease preventable blindness. Br J Ophthalmol 2001;85:1271-2.

\title{
Retinopathy of prematurity
}

\section{W V Good, S M Carden}

\section{An old problem comes calling again}

$\mathrm{T}$ hat retinopathy of prematurity (ROP) is occurring with increasing frequency in transitional economies is no longer debatable. Recognising this fact, the World Health Organization has identified ROP as a leading cause of vision impairment in children in the developing world. ${ }^{\prime}$ Others have identified ROP as an important, increasingly common, and potentially treatable condition in emerging economies. ${ }^{2}{ }^{3} \mathrm{No}$ doubt, improvements in neonatal care in various regions of the world are allowing smaller infants to survive. The question is, what constitutes a low birthweight infant in an emerging economy? To answer this question requires information on the demographics of ROP in these regions.

But demographics of ROP in transitional economies are hard to ascertain. Without this knowledge, it will be difficult to identify those infants who should be screened and treated. Reports of the disease occurring in larger than expected birthweight infants, in increasing frequency, in more mature infants, are alarming. These reports are well designed and carefully conducted but they are hampered by the chaos that exists in medical care delivery in the developing world. This must be especially true when premature infants are considered. Nothing should be left to chance in evaluating premature infant disease in the developing world, and no demographic data should be considered entirely reliable unless directly observed.

Consider the following. Many premature infants in transitional economies do not have access to hospital care ever, let alone early in their lives. They are born outside the hospital, often in rural environments. Scales for weighing children are absent or poorly calibrated, and estimates of gestational age may be based on guesswork, the lunar cycle, or nothing at all. Families are often caught by surprise by the premature arrival of their child, and may not know that medical care could improve survival. The healthcare delivery system is fragmented, unless the infant's family has resources to allow hospitalisation. Even so, the family would need to live near an urban centre to gain access to more modern types of treatment. Thus we may not know the number of premature infants in a given region. We know of some infants observed to have the disease, but cannot effectively estimate how many premature infants die or are not evaluated in the first months after birth.

Important obstacles stand in the way of better understanding the epidemiology of ROP in emerging economies. Some obstacles are obvious, such as insufficient medical resources to allow identification of premature infant demographics. Improved organisation of healthcare delivery will allow better characterisation of premature infants. A significant shortage of full time, geographically based specialists in ROP poses an additional obstacle. Visiting experts to the developing world help diagnose and treat ROP, with resulting transfer of skills. On the other hand, it is difficult for a visitor to reliably appreciate the extent of the problem of ROP in these developing regions. Consultants to developing regions are shown or told of cases. Increasingly, we hear that these cases are atypical, at least by western standards. We must assume the worst; that ROP is increasing, and that paradigms for screening and treatment may need modification for emerging economies. 
A treatment is available that can substantially reduce the rate of unfavourable outcomes, but surveillance for the disease is required

Some other obstacles to the study of the epidemiology of ROP are not so obvious. Equipment used to treat ROP rusts, is unfamiliar to practitioners, and/ or periodically requires servicing. Reliable haemoglobin saturation monitoring is highly problematic. In the United States it may take days to find appropriate personnel to repair broken laser equipment. This sort of support simply does not exist in the developing world. Recognition of ICROP (International Classification of Retinopathy of Prematurity) diagnostic findings requires ongoing review and calibration of doctors. Physical findings and management of ROP and its prevention are debated even in the Western world. Meanwhile, emerging economies are visited by Westerners with varying opinions about ROP classification findings, treatment timing, management of oxygen, management of other medical issues, use of oxygen, antioxidants, light in the nursery, respirators, and so on.

By now, the reader may be feeling less than sanguine about the potential for reducing the prevalence of blindness from ROP in emerging economies. Along comes the enlightened article by Chen and $\mathrm{Li}$ published in this issue of the $B J O(\mathrm{p} 268)$ to offer more than just a glimmer of hope that ROP can be studied and treated. Although these authors raise the spectre that a new epidemic of ROP may be emerging, they indirectly demonstrate that screening programmes are slowly coming into existence, at least in major metropolitan areas.

Implied in this paper is the fact that ROP surveillance has attained an important status in some regions of China. To be sure, it is very alarming that zone I cases are occurring, but recognition of these cases is the first step in prevention and management. It is also a concern that larger birthweight infants may develop severe ROP. Here, too, understanding the epidemiology of ROP in this part of the world will lead to better diagnosis and treatment.

The Western world has much to learn from research emanating from the developing world. To the extent that the epidemiology in these regions differs from that in the Western world, these differences may serve as a basis for understanding what initiates the disease, and what reduces its incidence. In the United States, the incidence of the disease has not changed much in the past 15 years, despite significant medical advances in the care of preterm infants. ${ }^{4}$ Chen and $\mathrm{Li}$ suggest that imprecise use of oxygen could be a factor in the apparently increasing incidence and severity of ROP in China. This is a plausible explanation, and one that might explain how and why ROP should occasionally be so severe in larger and more mature infants. Could oxygenation policy in the United States affect the incidence of the disease?

The fact remains that ROP is recognised with increasing frequency in developing regions of the world. A treatment is available that can substantially reduce the rate of unfavourable outcomes, but surveillance for the disease is required. Chen and $\mathrm{Li}$ are to be congratulated for studying the incidence of ROP in their country, and for bringing to our attention the alarming observation that many infants are blinded by ROP in China. Exactly how such surveillance should occur in China and other developing nations will depend on local factors. The first step in reducing blindness from ROP is recognising that the problem exists.

Br J Ophthalmol 2006;90:254-255.

doi: $10.1136 /$ bjo.2005.081166

\section{Authors' affiliations}

W V Good, Smith-Kettlewell Eye Research Institute, CA, USA

S M Carden, Royal Children's Hospital, Melbourne, Australia

Correspondence to: William V Good, 2318 Fillmore Street, San Francisco, CA 94115 , USA; good@ski.org

\section{REFERENCES}

1 WHO's mission for vision. Afr Health 1998:20:38.

2 Gilbert C, Fielder A, Gordillo L, et al. Characteristics of infants with severe retinopathy of prematurity in countries with low, moderate, and high levels of development: implications for screening programs. Pediatrics 2005; 115:e518-25.

3 Phan MH, Nguyen PN, Reynolds JD. Incidence and severity of retinopathy of prematurity in Vietnam, a developing middle-income country. $J$ Pediatr Ophthalmol Strabismus 2003:40:208-12

4 The Early Treatment for Retinopathy of Prematurity Cooperative Group. The incidence and course of retinopathy of prematurity: findings from the early treatment for retinopathy of prematurity study. Pediatrics 2005; 116:15-23.

\section{The calculation and use of economic burden data}

\section{K D Frick, S M Kymes}

\section{Even in a developed economy, visual impairment can limit further economic development}

$\mathrm{T}$ aylor et al writing in this issue of the BJO (p 272) are to be congratulated for their excellent description of the economic burden of visual impairment in Australia. While most in the eye care community have always assumed that visual impairment represents an important social burden, the authors have shown that the absolute economic burden of visual impairment ranks with cancer, dementia, and arthritis. The impact relative to the entire Australian economy $(0.6 \%$ of the Australian GDP) also emphasises the non-trivial nature of the burden of visual impairment. The results should catch the attention of health policy makers because they suggest that, even in a developed economy, visual impairment can limit further economic development.

In order to make appropriate use of the important findings, readers must understand the inputs into the burden calculation, the way in which a measure of burden can fit into cost effectiveness or cost benefit models, and notable points about the methods used. Epidemiological and economic data are inputs for a national burden calculation. The epidemiological information is either prevalence or incidence; Taylor et al used prevalence, and this has implications for how the results can be incorporated into an economic evaluation. The economic data include expenses related to prevention and treatment of conditions leading to visual impairment, productivity loss among the visually impaired population, and expenses attributable to informal 